\section{Better writing and more space needed online}

SIR - The World-Wide Web is remarkable as a vehicle for communicating scientific discoveries. Online journals unite distant researchers and inspire worldwide collaborations.

However, despite these

advantages, there is a growing risk that papers published today are less successful in meeting their objectives than in the past.

To ensure clear communication, most journals encourage authors to write for a broad audience. But most published papers still compress too much information into uncomfortably short articles, leading to convoluted sentences, specialized terminology and a proliferation of abbreviations. Errors in grammatical style result in impenetrable and ambiguous texts that seriously undermine the scientific literature. This need not be the case.

Electronic publishing could offer authors limitless space to explain their ideas and discuss their new findings. Surprisingly, though, online manuscripts are often bound by the same space constraints as print manuscripts.

Authors are instructed to conform to print-journal guidelines, leading many to redirect essential material to online Supplementary Information. The recent explosion in Supplementary Information is problematic: it seems to have no standard format among different journals, and there is a common misperception that data in Supplementary Information have escaped peer review. It can be a nuisance for readers too. For example, if they want to peruse articles away from their computers and haven't downloaded the related Supplementary Information, it may be impossible for them to understand or fully evaluate the papers' merits.

The scientific article in 2008 is on the cusp of change, with one foot in the past and one in the future. Science journals should shed the constraints of the old media and exploit the advantages of the new, to offer readers easy and enjoyable access to the scientific literature.

Even if journals are successful at reinventing themselves, it won't be adequate unless the quality of writing in scientific manuscripts improves. Paradoxically, the deterioration in science writing seems to coincide with the swell in e-publications - at a time when the need to communicate advances in science is more urgent than ever. The quality of writing needs to match the power of today's e-publishing technology.

Linda Cooper Redpath Museum, Faculty of Science, McGill University, Montreal, Quebec H3A 2K6 Canada e-mail: linda.cooper@mcgill.ca

\section{Languages: Catalan speakers learn a wider range}

SIR - Jose M. Rojo claims, in his Correspondence 'Schools in a third of Spain teach only in minority languages' (Nature 454, 575; 2008), that public education is not available in Spanish in schools in Catalonia, Mallorca and Valencia. However, in Catalonia, the Spanish-language skills of schoolchildren completing their education are equivalent to those of children across Spain.

The Programme for International Student Assessment (www.pisa.oecd.org) indicates that the learning capacities of Catalan and Spanish schoolchildren in science and mathematics are not dependent on whether they receive a bilingual education. This conclusion flies in the face of the manifesto mentioned in Rojo's letter, which seeks to enforce a Spanish rather than bilingual education, and to relegate Basque, Catalan and Galician to a linguistic ghetto.

A recent study shows that, in most Spanish regions, between half and two-thirds of

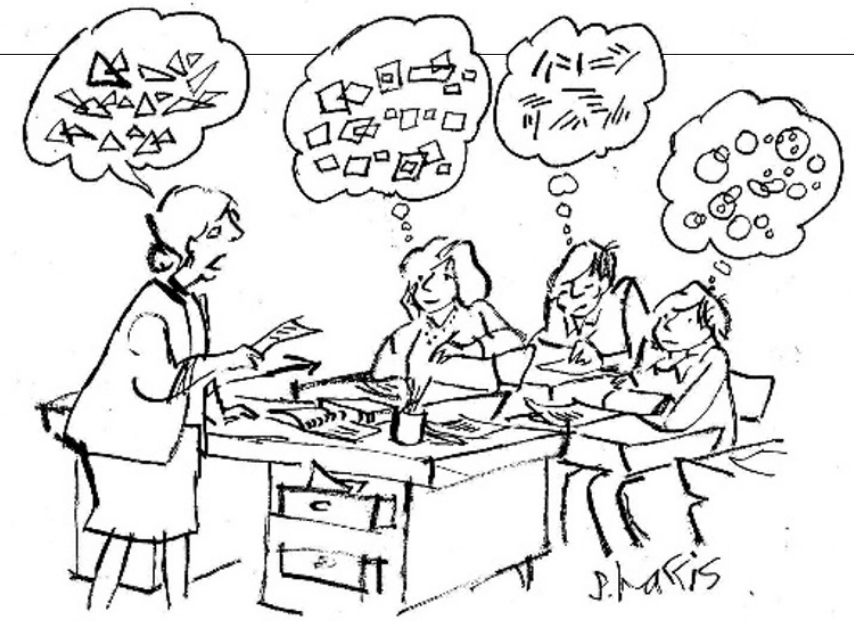

the population does not know a foreign language (F. Alvira Martín and J. García López Cuad. Inform. Econ. 205, 119-138; 2008; http://tinyurl.com/64ngkh). But in Catalonia and the Balearic Islands, where most of the population understands both Catalan and Spanish, about threequarters of the population can also speak a foreign language. It might be in the better interests of Spain and science to improve the present knowledge of foreign languages and encourage an effective multilingual education, rather than striving to enforce monolingual Spanish education. Antoni Rosell-Melé Institute of Environmental Science and Technology (ICTA), Universitat Autònoma de Barcelona (UAB), Edifici $\mathrm{Cn}$ - Campus UAB, 08193 Bellaterra, Catalonia, Spain e-mail: antoni.rosell@uab.cat

\section{Languages: Spain's minority-language speakers are bilingual}

SIR — In his Correspondence 'Schools in a third of Spain teach only in minority languages' (Nature 454, 575; 2008), Jose M. Rojo complained about the impossibility of studying in Spanish in one-third of the public schools in Spain. This is, at best, misleading. The Catalan schooling system, for example, does indeed promote the use of Catalan, but native Catalan students are as fluent in Spanish as their monolingual counterparts. The political manifesto Rojo cites to emphasize his point is riddled with contradictions, is not endorsed by any linguists and does not belong in the pages of Nature.

Jesús Purroy Scientific Department, Parc Científic de Barcelona, Baldiri Reixac 10, 08028 Barcelona,

Catalonia, Spain

e-mail:jpurroy@pcb.ub.cat

Readers are welcome to comment at http://tinyurl.com/5e6ltj

\section{Religion: science is partially based on faith}

SIR - Andrew Brown's Obituary of John Templeton (Nature 454, 290; 2008) and your Editorial ('Templeton's legacy' Nature 454, 253-254; 2008) both touch upon the philanthropist's interest in science and faith. Some might argue that science and faith should be kept separate, although others have no problem in reconciling the two. I am reminded of the different perspective on this eternal debate that is offered in astrophysicist Carl Sagan's science-fiction novel Contact (Orbit, 1985) - though not in the film of the same name, which is only very loosely based on the book.

Contact recounts an astronomer's successful search for alien intelligence. It also has a subplot that science and religion are, in fact, closer than the two camps imagine. Scientists' use of the scientific method pragmatically includes faith. A scientist must first conceive 